Cell Research (2003); 13(4):239-249

http://www.cell-research.com

\title{
Drug resistance in the sexually transmitted protozoan Trichomonas vaginalis
}

\author{
Rebecca L DUNnE ${ }^{1,2}$, Linda A DUNN ${ }^{1}$, Peter UPCROFT ${ }^{1}$, Peter J O'DONOGHUE ${ }^{2}$, Jacqueline A \\ $\mathrm{UPCROFT}^{1, *}$ \\ 1 The Queensland Institute of Medical Research; The Australian Centre for International and TropicalHealth \\ and Nutrition; Brisbane, Queensland 4029, Australia \\ 2 The School of Molecular and Microbial Science, University of Queensland, Brisbane, Queensland 4072, \\ Australia
}

\begin{abstract}
Trichomoniasis is the most common, sexually transmitted infection. It is caused by the flagellated protozoan parasite Trichomonas vaginalis. Symptoms include vaginitis and infections have been associated with preterm delivery, low birth weight and increased infant mortality, as well as predisposing to HIV/AIDS and cervical cancer. Trichomoniasis has the highest prevalence and incidence of any sexually transmitted infection. The 5nitroimidazole drugs, of which metronidazole is the most prescribed, are the only approved, effective drugs to treat trichomoniasis. Resistance against metronidazole is frequently reported and cross-resistance among the family of 5-nitroimidazole drugs is common, leaving no alternative for treatment, with some cases remaining unresolved. The mechanism of metronidazole resistance in T. vaginalis from treatment failures is not well understood, unlike resistance which is developed in the laboratory under increasing metronidazole pressure. In the latter situation, hydrogenosomal function which is involved in activation of the prodrug, metronidazole, is down-regulated. Reversion to sensitivity is incomplete after removal of drug pressure in the highly resistant parasites while clinically resistant strains, so far analysed, maintain their resistance levels in the absence of drug pressure. Although anaerobic resistance has been regarded as a laboratory induced phenomenon, it clearly has been demonstrated in clinical isolates. Pursuit of both approaches will allow dissection of the underlying mechanisms. Many alternative drugs and treatments have been tested in vivo in cases of refractory trichomoniasis, as well as in vitro with some successes including the broad spectrum anti-parasitic drug nitazoxanide. Drug resistance incidence in $\mathrm{T}$. vaginalis appears to be on the increase and improved surveillance of treatment failures is urged.
\end{abstract}

Key words: Trichomonas vaginalis, metronidazole, pyruvate: ferredoxin oxidoreductase, ferredoxin, hydrogenase, drug resistance.

* Correspondence: Dr. Jacqueline A UPCROFT

The Queensland Institute of Medical Research, The Australian Centre for International and Tropical Health and Nutrition, Brisbane,Queensland 4029, Australia. Tel: 0061733620369 Fax: 0061733620105 (fax) E-mail: jacquiU@qimr.edu.au

\begin{abstract}
Abbreviations: b.i.d, twice a day; CoA, coenzyme A; Fd, ferredoxin; HYD, hydrogenase; MDR, multiple drug resistance; ME, malic enzyme; MIC, minimal inhibitory concentration; MLC, minimum lethal concentration; PFOR, pyruvate:ferredoxin oxidoreductase; Pgp, P-glycoprotein; q.i.d, four times a day; t.i.d, thrice a day; Tvpgp1, Trichomonas vaginalis $\mathrm{P}$-glycoprotein 1 ; d, day; $\mathrm{m}$, month; wk, week; y, year.
\end{abstract}




\section{INTRODUCTION}

Drug resistance amongst the protozoa is an increasing problem with relatively few available drug alternatives. Poorly supervised treatment regimes and chemoprophylactic use of antimicrobials has resulted in the inefficacy of valuable drugs such as chloroquine in the treatment of falciparum malaria[1]. Cross-resistance to chloroquine and its analogues now occurs in almost all endemic areas. Resistance in the anaerobic protozoan parasite, Trichomonas vaginalis which was reported as early as 1962 is similarly at risk of becoming resistant to all recommended therapeutics [2]. It is the most common sexually transmitted infection worldwide with an estimated billion people infected at any one time[3, 4]. The 5-nitroimidazole family of drugs, specifically metronidazole and tinidazole, is the only class of drugs approved for the treatment of trichomoniasis with estimates of up to $10 \%$ of infections not responding to treatment in the United States[4]. Resistant organisms are cosmopolitan in distribution and are of considerable concern as Trichomonas infections are linked to vaginal HIV transmission[5-7].

$T$. vaginalis discovered by Alfred Donné in 1836, is an amitochondrial, microaerotolerant flagellate of the human urogenital tract. Each trophozoite possesses 4 anterior flagella and a single recurrent flagellum incorporated into an undulating membrane which is supported by a non-contractile costa. The cell body is longitudinally pierced by a thin, hyaline structure called the axostyle, which protrudes at the posterior. The nucleus is contained within a porous envelope typical of higher eukaryotes. Both free, motile and adhered, amoeboid forms have been described[8]. Multiple granular organelles, the hydrogenosomes, are characteristic of $\mathrm{T}$. vaginalis and are involved in the parasite's metabolic pathways. The origin of the hydrogenosome remains under debate and is believed to be either analogous with the mitochondria having shared a common ancestor, the a-Gram negative proteobacteria[9], or alternatively, a direct derivative of the mitochondrion itself[10]. T. vaginalis trophozoites divide via longitudinal binary fission. It has no known cyst stage. However, pseudocyst formation has been described in cells undergoing environmental stress[11].

$T$. vaginalis is found on every continent and within every culture with highest occurrences in South and South East Asia, sub-Saharan Africa and amongst the under-privileged[3]. Approximately 50\% of infections present with non-typical symptoms ranging from vaginitis, cervicitis and vulvitis in women, to urethritis, prostatitis and pruritis in men[12, 13]. Neonatal ocular and respiratory infections have also been described in neonates of infected mothers[14, 15]. Chronic infections have been associated with pre-term birth and low birth-weight neonates, cervical cancer and increased HIV transmission amongst the most alarming[16-18]. Infection rates have been reported as high as 67\% in Mongolia in 1998[19], 40-60 \% in Africa, $40 \%$ in Indigenous Australians over 40 years of age [20], and $46 \%$ in highland women of Papua New Guinea[21, 22]. Trichomoniasis has the highest prevalence and incidence of any STI, and its eradication may well be the single most cost-effective step in HIV incidence reduction[23, 24].

\section{Treatment of trichomoniasis}

Metronidazole was originally synthesised and approved for the treatment of trichomoniasis in 1959 [25]. Recommended treatment regimes range from a single 1.5 or $2 \mathrm{~g}$ oral dose to split doses of $500 \mathrm{mg}$ twice daily over a period of $7 \mathrm{~d}[26,27]$. Although metronidazole and tinidazole are the recommended drugs to treat trichomoniasis, their broad antimicrobial spectrum extends across the other anaerobic protozoa including, Entamoeba histolytica, Giardia duodenalis and Blastocystis hominis and anaerobic bacteria, Helicobacter pylori, Bacteroides spp and Clostridium spp[28]. Metronidazole is also valued for its prophylactic qualities in gynecological and other surgery, ease of administration via oral, topical, intravaginal or intravenous routes, few side effects and it is relatively inexpensive[28].

\section{Energy metabolism}

$T$. vaginalis relies on substrate-level fermentative pathways for the production of ATP. Glycolysis occurs within the cytosol and adheres to classical pathways with little alteration. Pyruvate generated via glycolysis is transported into the hydrogenosome and decarboxylated by the key hydrogenosomal enzyme pyruvate:ferredoxin oxidoreductase (PFOR) to form 
acetyl-CoA. Acetate is produced as an end product via the transfer of CoA to succinate. CoA is released by succinate thiokinase resulting in the production of ATP. Ferredoxin (Fd) accepts electrons generated by PFOR. Hydrogenase (HYD) then couples electrons to hydrogen ions forming molecular hydrogen as an end product [4, 29] (Fig 1). Similar metabolic pathways have been described in the ancient protozoan, G. duodenalis $[4,30,31]$ and also in the anaerobic bacterium $\mathrm{H}$. pylori[32]. However these organisms lack the compartmental organisation of the hydrogenosome.

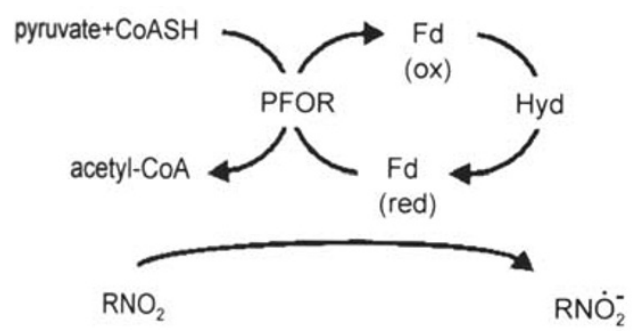

Fig 1. Anaerobic metabolism of Trichomonas vaginalis. Pyruvate from glycolysis enters the hydrogenosome where it is decarboxylated by the membrane-bound enzyme, pyruvate:ferredoxin oxidoreductase (PFOR) which donates electrons to ferredoxin (Fd). The decarboxylation of pyruvate forms acetate and ultimately ATP. Fd is reoxidised by hydrogenase (Hyd) with molecular hydrogen as a final end product in the electron transport chain within the hydrogenosome. The prodrug metronidazole $\left(\mathrm{RNO}_{2}\right)$ enters the hydrogenosome via passive diffusion where it competes with hydrogenase for electrons from $\mathrm{Fd}$. The reduction of metronidazole activates the drug to its toxic nitro-radical form. In the presence of oxygen, futile recycling occurs, converting the radicals back to the prodrug. ox, oxidised; red, reduced.

\section{Mechanisms of drug action}

As well as being the metabolic powerhouse of the cell, the hydrogenosome plays a critical role in drug activation[29, 33]. Metronidazole enters both the cell and organelle via passive diffusion as a prodrug and competes with the terminal enzyme hydrogenase as an electron acceptor from Fd. Activation of the drug occurs when an electron is transferred to the all important nitro-group forming a toxic nitro-radical (Fig 1) $[4,29,34]$. In bacteria, the radicals cause chromosome breakage and cell death[35]. However, the precise target in a nucleated organism is unknown with proteins and protein trafficking likely major targets [29]. In addition to the toxic radicals, the production of molecular hydrogen is impaired in the presence of metronidazole, resulting in an increase of intracellular hydrogen peroxide[29, 36]. Under aerobic conditions in vitro, oxygen converts radicals back to the prodrug. Thus, in susceptibility assays carried out aerobically, drug inhibitory concentrations are higher than those carried out anaerobically[4, 34, 37].

\section{Clinical drug resistance}

Clinical isolates derived from treatment failures typically show resistance to metronidazole under aerobic conditions while some also exhibit anaerobic resistance. In the assay system recently reported by us, a clinically resistant isolate BRIS/92/STDL/B7268 (B7268) has an anaerobic minimal inhibitory concentration (MIC) of $25 \mu M$ metronidazole, while the MIC of susceptible isolates is 3-6 $\mu \mathrm{M}$ [34] (Tab 1). Under

Tab 1. MLCs for Trichomonas vaginalis in drug susceptibility assays

\begin{tabular}{lcc}
\hline Isolate & MLC (mM)AN & MLC mM)A \\
\hline BRIS/92/STDL/B7268 & 25 & $>200$ \\
BRIS/98/BSHC/11147 & 6.3 & 50 \\
BRIS/92/STDL/F1623 & 3.2 & 25 \\
BRIS/92/STDL/F1623-M1 & $>100$ & Dead \\
\hline
\end{tabular}

\footnotetext{
${ }^{\mathrm{AN}}$ Assays conducted under anaerobic conditions

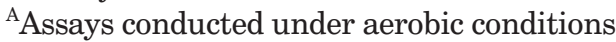

Metronidazole, $1 \mu \mathrm{M}$ is equal to $0.17 \mu \mathrm{g} / \mathrm{ml}$. Metronidazole susceptibility assays were conducted over $48 \mathrm{~h}$ under anaerobic conditions[34]. B7268 was isolated from a patient suffering prolonged refractory trichomoniasis[41]. 11147 was isolated from a patient who was successfully treated with standard doses of metronidazole[34]. F1623-M1 is the syngeneic highly metronidazole-resistant line developed from the metronidazole-susceptible isolate F1623 and is maintained in culture together with $400 \mu \mathrm{M}$ metronidazole[43].
} 
aerobic conditions, B7268 has an MIC > $200 \mu M(34$ $\mu \mathrm{g} / \mathrm{ml}$ ) metronidazole (Tab 2). Depending on the assay system used, aerobic MICs of metronidazole on clinically resistant isolates have been reported to range from $25 \mu \mathrm{g} / \mathrm{ml}$ to $>200 \mu \mathrm{g} / \mathrm{ml}$ (Tab 2). The assortment of assays reported in the literature prevent direct comparisons but the values incorporated in Tab 2 give some idea of the levels of resistance reached by several metronidazole-resistant clinical isolates. Resistance typically arises following multiple courses of metronidazole treatment for either trichomoniasis or another condition and in most cases, symptoms can be finally resolved with high doses of tinidazole and/ or metronidazole over extended periods but in some instances these high dose, poorly tolerated treatments are also unsuccessful (Tab 3).

\section{In vitro resistance}

Aerobic or, so called, partial resistance is demonstrated when oxygen competes with metronidazole for electrons and has been attributed to impaired oxygen scavenging pathways allowing increased futile recycling of metronidazole in comparison with sensitive strains[38] (Fig 1). Reports of aerobically resistant isolates indicate that they are frequently sensitive under anaerobic conditions[38-40]. However, B7268, established in our laboratory from a Brisbane patient with refractory infection[41], displays both high aerobic and anaerobic resistance to metronidazole. Anaerobic or complete resistance is selectively developed in vitro by continuously culturing trophozoites in increasing concentrations of metronidazole as we and others have done[42, 43]. We have developed several anaerobically metronidazole-resistant lines typically able to survive in culture medium containing $>400 \mu \mathrm{M}$ metronidazole[43]. In comparison, the clinically metronidazolesusceptible parent strains, from which the highly resistant lines were derived, have MICs as low as $3 \mu \mathrm{M}$ [34] (Tab 1). The process of inducing drug resistance in an established sensitive parent strain eventually results in syngeneic parent and drug-resistant lines from which the critical changes involved in the mechanism of drug resistance can be determined, and readily compared with clinical isolates, as we have argued extensively[4, 44].

\section{Mechanisms of resistance}

Initially we induced high levels of resistance in the clinically susceptible strain BRIS/92/STDL/F1623 (F1623) by continuous culturing in sub-lethal, increasing concentrations (finally reaching $1 \mu M$ ) of metronidazole,[43]. This confirmed similar data by Kulda et al[42], where 2 strains, one susceptible and one aerobically resistant, were cultivated in increasing concentrations of metronidazole for almost 2 years until the parasites were able to survive very high concentrations of metronidazole. Since we had shown that the PFOR activity and Fd levels were decreased in highly metronidazole-resistant Giardia parasites[30, 45], we compared transcription levels of these two proteins in our syngeneic lines of metronidazole-resistant and -susceptible T. vaginalis parasites. Radioactively labelled probes derived from $764 \mathrm{bp}$ of the $5^{\prime}$ region of the $\mathrm{PFOR}$ gene and a $500 \mathrm{bp}$ product of the Fd gene were hybridised with mRNA from the syngeneic lines. Northern blot analyses revealed that the 4 . $4 \mathrm{~kb}$ band of PFOR mRNA and Fd mRNA were represented only in the susceptible strain[43]. Our data [43], that of Kulda et al[42] and Quon et al[46], as well as the data of Land et al[36] working with the cattle parasite, Tritrichomonas foetus[36], revealed that mRNA levels of the hydrogenosomal proteins PFOR, HYD, Fd and malate enzyme (ME) were reduced by up to $100 \%$, and hydrogenosomal function was generally depleted in the resistant lines. However, Land et al[36] and Jaroslav Kulda (personal communication) have recently reported that the depleted hydrogenosomes are present in the resistant cells in similar numbers to sensitive cells but they were significantly smaller in the resistant line. In our experience the typical brown colour of $\mathrm{T}$. vaginalis trophozoites (particularly apparent in pelleted cells) due to Fe-S cluster containing proteins found in the hydrogenosomes is not evident in highly metronidazole-resistant cells, consistent with the down-regulation of hydrogenosome function.

Clinically metronidazole-resistant parasites grow aerobically whereas the laboratory-induced, highly resistant lines do not and therefore, it has been argued that they would not survive in vivo. Rasoloson et al[38] confirmed that decreased Fd expression was not a mechanism of resistance in aerobically resistant clinical isolates, as observed in highly metronidazoleresistant laboratory lines, and concluded that the mechanism of aerobic resistance involves impaired 
Tab 2. Metronidazole resistance of $\mathrm{T}$. vaginalis isolated from cases of treatment failures

\begin{tabular}{|c|c|c|c|c|}
\hline \multirow[t]{2}{*}{ Isolate } & \multicolumn{2}{|c|}{ MLC orM MIC } & \multirow[t]{2}{*}{ Country } & \multirow[t]{2}{*}{ Ref } \\
\hline & $(\mu M)$ & $(\mu \mathrm{g} / \mathrm{ml})$ & & \\
\hline BRIS/92/STDL/F1623* & 25 & 4.25 & Australia & 34 \\
\hline BRIS/92/STDL/B7268 & $>200$ & $>34$ & Australia & 34 \\
\hline BRIS/98/BHSC/11147* & 50 & 8.5 & Australia & 34 \\
\hline CDC (104 isolates) & 2336 & 397 & USA & 59 \\
\hline ATL (6 isolates) & $>50$ & $>8.5$ & USA & 79 \\
\hline MSA (31 isolates) & $>50$ & $>8.5$ & USA & 79 \\
\hline Other (5 isolates) & $>50$ & $>8.5$ & USA & 79 \\
\hline Clinical isolate 1 & 294 & 50 & Spain & 80 \\
\hline Clinical isolate 2 & 294 & 50 & Spain & 80 \\
\hline Case1 & 147 & 25 & New Zealand & 7 \\
\hline Case2 & 147 & 25 & New Zealand & 7 \\
\hline Clinical isolate 1 & 46 & 7.8 & Finland & 62 \\
\hline Clinical isolate 2 & 282 & 48 & Finland & 62 \\
\hline Clinical isolate 3 & 823 & 140 & Finland & 62 \\
\hline
\end{tabular}

All assays were conducted under aerobic conditions.

* Susceptible isolates for comparison

Isolate resistance values were either reported as MLC or MIC. Where multiple isolates are included, the median MIC or MLC is given. In the cases where no strain identification was provided, isolates were numbered in the order in which they were reported.

Tab 3. Case histories of trichomoniasis treatment failures

\begin{tabular}{|c|c|c|}
\hline Treatment histories including patient age & Final cure & Ref. \\
\hline $54 \mathrm{y}, 18 \mathrm{~m}$ infection, multiple treatment failures & $2 \mathrm{~g} \mathrm{M}$ orally b.i.d and $500 \mathrm{mg}$ vaginally, $16 \mathrm{~d}$ & 41 \\
\hline $\begin{array}{l}39 \text { y, } 8 \mathrm{~m} \text { infection, unsuccessful treatments with } \mathrm{M} \text {, } \\
\mathrm{T} \text { and } \mathrm{A}\end{array}$ & Acetarsol pessaries, b.i.d for $10 \mathrm{~d}$ & 65 \\
\hline 29 y, $6 \mathrm{~m}$ severe recurrent vulvo vaginitis & $800 \mathrm{mg} \mathrm{T}$ orally and $1 \mathrm{~g}$ vaginally, t.i.d for $7 \mathrm{~d}$ & 7 \\
\hline 19 y, $3 \mathrm{~m}$ unsuccessful treatment including $\mathrm{O}$ & $800 \mathrm{mg}$ T orally, t.i.d for $7 \mathrm{~d}$ & 7 \\
\hline $\begin{array}{l}32 \mathrm{y}, 3 \text { y infection, unsuccessful treatments with } \mathrm{M} \text {, } \\
\text { Tet and Amp }\end{array}$ & $\begin{array}{l}\text { Intense CT including double zinc sulfate douches, } \\
500 \mathrm{mg} \mathrm{M} \text { suppositories, } 20 \mathrm{~m}\end{array}$ & 67 \\
\hline $\begin{array}{l}28 \mathrm{y}, 4 \text { y infection, treatment failures include } \mathrm{N} \text {, } \\
\text { Trm, peroxide douche, sulphonamide and PI }\end{array}$ & $\begin{array}{l}\text { Zinc sulfate douche, } 500 \mathrm{mg} \text { M suppositories b.i.d } \\
\text { and M } 400 \mathrm{mg} \text { orally t.i.d for } 3 \mathrm{~d} \text {, M } 200 \mathrm{mg} \text { t.i.d. } 4 \mathrm{~d} \text {, } \\
\text { zinc sulfate douche and } \mathrm{M} \text { suppositories nightly } 7 \mathrm{~d} \text {, } \\
\text { then every other day for } 14 \mathrm{~d}\end{array}$ & 67 \\
\hline $\begin{array}{l}39 \text { y, } 3 \text { y recurrent infection, treatment failures inclu- } \\
\text { ding } M \text { and } O x\end{array}$ & Zinc sulfate douche, $500 \mathrm{mg}$ M suppositories b.i.d & 67 \\
\hline $\begin{array}{l}25 \mathrm{y}, 4 \mathrm{~m} \text { infection, treatment failures including oral } \\
\text { and vaginal } \mathrm{M} \text {, Amp and Tet. }\end{array}$ & $\begin{array}{l}\text { CT b.i.d, M } 200 \mathrm{mg} \text { t.i.d } 7 \mathrm{~d} \text {, nightly zinc sulfate } \\
\text { douches plus } 1 \mathrm{~g} \text { M suppository for } 7 \mathrm{~d}\end{array}$ & 67 \\
\hline $\begin{array}{l}33 \mathrm{y}, 4 \text { y infection, treatment failures including } \mathrm{M}, \mathrm{P} \\
\text { and } \mathrm{F}\end{array}$ & $\begin{array}{l}\text { T } 500 \mathrm{mg} \text { orally q.i.d and } 500 \mathrm{mg} \text { intravaginally b.i.d for } \\
14 \mathrm{~d}\end{array}$ & 81 \\
\hline $\begin{array}{l}42 \mathrm{y}, 10 \mathrm{~m} \text { infection, treatment failures included } \mathrm{E} \text {, } \\
\mathrm{M}, \mathrm{T}, \mathrm{N}, \mathrm{Mb} \text {, PI and lactobacilli vaccines }\end{array}$ & $250 \mathrm{mg}$ paromomycin intravaginally, $7 \mathrm{~d}$. & 82 \\
\hline
\end{tabular}

Isolates were derived from all patients and confirmed to be metronidazole resistant. A, amoxicillin; Amp, ampicillin; CT, combination therapy; E, erythromycin; F, furazolidone; M, metronidazole; Mb, mebendazole; N, nimorazole; O, ornidazole; Ox, oxytetracycline; P, prochloroperazine; PI, providone iodine; T, tinidazole; Tet, tetracycline; Trm, trimidazole; d, day; m, month; y, year. 
Tab 4. Reversal of resistance after removal of metronidazole from culture medium

\begin{tabular}{lllll}
\hline Isolate & & \multicolumn{3}{c}{ MIC } \\
\hline & $0 \mathrm{wk}$ & $8 \mathrm{wk}$ & $10.5 \mathrm{wk}$ & $21 \mathrm{wk}$ \\
BRIS/92/STDL/F1623 & 3 & 3 & 3 & 3 \\
BRIS/92/STDL/F1623-M1 & $25>100$ & $6.25-12.5$ & $6.25-12.5$ & $6.25-12.5$ \\
BRIS/92/STDL/B7268 & $25-1002$ & $5-100$ & $25-100$ & $25-100$ \\
\hline
\end{tabular}

Metronidazole susceptibility assays were conducted under anaerobic conditions before (at $0 \mathrm{wk}$ ) and after $21 \mathrm{wk}$ following removal of metronidazole from the culture medium. MIC are given in mM metronidazole and were determined after $48 \mathrm{~h}$ incubation with metronidazole in assays ( $1 \mu \mathrm{M}$ is equal to $0.17 \mu \mathrm{g} / \mathrm{ml})[34]$.

F1623-M1 is metronidazole-resistant (see Tab 1) and at 0 wk was maintained in $400 \mu \mathrm{M}$ metronidazole in culture medium, thereafter it was grown without metronidazole. Clinically metronidazole-resistant isolate B7268 is never maintained in the presence of metronidazole. All assays were repeated in quadruplicate in the same plate.

oxygen scavenging pathways.

When metronidazole is removed from the culture medium of the highly metronidazole- resistant lines, they do not immediately revert to sensitivity and even after several months in the absence of drug still display some level of resistance (Tab 4). While preliminary results of ours indicate no obvious difference between the genotypes of metronidazole-susceptible and -resistant syngeneic lines (data not shown), clearly such slow and incomplete reversion to susceptibility suggests genetic rearrangements have occurred during the long process of induction of resistance.

\section{Alternative mechanisms of resistance}

We have demonstrated the existence of two alternative 2-keto acid oxidoreductases (OR), KOR1 and KOR2, in metronidazole-resistant $\mathrm{T}$. vaginalis[43]. KOR1 is present in both drug-resistant and drug-sensitive cells and its activity was evident in Triton extracts of cells. KOR2 activity was observed only in metronidazole-resistant cells. KOR 1 and 2 do not donate electrons to $\mathrm{Fd}$ since there is no detectable $\mathrm{Fd}$ mRNA in the metronidazole-resistant cells in which we identified both alternative ORs. Amongst the anaerobes in general, there are many alternative energy pathways available; for example, four different ORs that preferentially utilise alternative keto acid substrates to pyruvate have been identified in Thermococcus litoralis[47]. The anaerobic protozoa, unlike higher eukaryotes, have retained diversity in usage of alternative keto acids for energy production and in $\mathrm{T}$. vaginalis indolepyruvate is a preferred substrate of the two KOR enzymes[43, 48].

In addition to showing that $\mathrm{Fd}$ levels were reduced in metronidazole-resistant T. vaginalis, Quon et al[46] identified a point mutation within the 5 ' flanking region of the $\mathrm{Fd}$ gene which they suggested interfered with DNA binding proteins resulting in decreased transcription of the $\mathrm{Fd}$ gene. Also working with the $\mathrm{Fd}$ gene but this time in T. foetus, Land et al[49] were able to show that transformation of metronidazoleresistant cells with the Fd gene, which was expressed in vivo, resulted in partial reversion to sensitivity of the cells.

Kulda and his colleagues[29, 50] maintain that PFOR deficiency in $\mathrm{T}$. foetus completely precludes metronidazole activation, while $\mathrm{T}$. vaginalis possesses an additional drug-activating system which must be eliminated before full resistance is achieved. This alternative pathway involves NAD-dependent ME in the oxidative decarboxylation of malate in hydrogenosomes and the subsequent reduction (or activation of metronidazole) via $\mathrm{NADH}$ :ferredoxin oxidoreductase and $\mathrm{Fd}$.

Other changes in metronidazole-resistant $T$. vaginalis

Downregulation of hydrogenosomal function is not the only change observed in our highly metronidazole-resistant lines. Morphological changes also occur. We have shown that adherence to culture tubes and 96-well plates is dramatically increased to almost $100 \%$ in the metronidazole-resistant lines F1623-M1 and BRIS/92/STDL/B7708-M1 in comparison to their metronidazole-susceptible parent strains F1623 and BRIS/92/STDL/B7708 which adhere less than 20\% (data not shown). Impaired motility and increased generation time are also characteristic of the resistant 
lines. These changes only partially reverted on removal of drug over several months. Typically $\mathrm{T}$. vaginalis isolates display a range of morphologies from highly motile to mostly attached and this is the first time that the phenomenon of induced morphological changes has been reported associated with exposure to metronidazole.

\section{Multiple Drug Resistance}

P-glycoproteins (Pgp) are membrane-bound ATPdependent efflux pumps comprising two homologous halves each exhibiting an ATP binding cassette associated with 6 transmembrane alpha-helices[51]. The overexpression of Pgps is directly linked to the multiple drug resistance (MDR) phenotype observed in both mammalian tumour cells and the protozoan parasites Entamoeba and Leishmania[51-55]. The presence of Pgps has been documented, though not intensively studied in $T$. vaginalis[56]. $T$. vaginalis Pgp (Tvpgp1) is similar in sequence to mammalian Pgps and is present in 2 copies within the genome. Increased expression of Tvpgp1 mRNA has been demonstrated in several resistant strains to levels ranging from 2-3 fold to as high as 20 fold in one strain but gene copy numbers are not increased in resistant strains and four out of the 7 resistant strains investigated had only a single copy of the Tvpgp1 gene[56]. No clear mechanism of resistance has been shown in clinically resistant isolates of $\mathrm{T}$. vaginalis and it is unclear whether Pgps play a role in resistance to metronidazole in these isolates. However, transport of drug out of the cell is an obvious candidate mechanism. A number of lipophilic agents, including verapamil the calcium ion channel blocker, are able to reverse the MDR phenotype in vitro[51, 53, 57, 58] but many of these agents are highly toxic to the host; consequently a number of pharmacologically relatively inert surfactants have also been trialed. Cremophor EL and Solutol HS 15 are fatty acid ester surfactants and are proven modulators of MDR[57]. We have carried out preliminary experiments with the clinically metronidazoleresistant line B7268 and shown that inclusion of Cremophor EL $(0.05 \%-0.2 \%)$ or Solutol $(874 \mu \mathrm{M})$ in metronidazole susceptibility assays reduces the MIC from $50 \mu \mathrm{M}$ to $12.5 \mu \mathrm{M}$. Addition of 100-200 $\mu \mathrm{M}$ verapamil also reduces the MIC restoring susceptibility to around $6 \mathrm{~m} \mathrm{M}$. This is suggestive of a classical
MDR pathway operating in the clinically metronidazole-resistant line, B7268, and we are undertaking further work using other clinically resistant lines and other modulators to resolve the questions regarding the mechanisms of metronidazole resistance in clinical isolates. Interestingly, when MDR modulators are included in assays using our laboratory induced, highly metronidazole-resistant $\mathrm{T}$. vaginalis lines, no reduction is seen in metronidazole MIC values, compared with metronidazole alone treatment, which suggests that down-regulation of the hydrogenosome function is the major drug resistance mechanism operating in these lines. The data so far elicited suggest multiple mechanisms which must overlap in function, depending on the level of resistance, culminating in the very high anaerobic resistance seen in the laboratory-induced isolates.

\section{Cross-resistance}

Cross-resistance among 5-nitroimidazole derivatives has been broadly observed in $\mathrm{T}$. vaginalis isolates. A recent study by Crowell et al[59] evaluated the sensitivity of 104 clinically metronidazole-resistant isolates to metronidazole and tinidazole. Tinidazole MLCs were the same as metronidazole MLCs for $38 \%$ of the isolates and lower (indicating tinidazole to be more effective than metronidazole - to varying degrees) in $60 \%$ of isolates. This emphasises a significant level of cross-resistance between the two 5-nitroimidazole drugs but also that cross-resistance may be incomplete. It has been previously documented that metronidazole-refractory cases have been finally cured by tinidazole, albeit at very high doses (Tab 3). Sobel and Brown[60] successfully treated 22 out of 24 cases of metronidazole- refractory infections with high doses of oral (500 mg q.i.d) and intravaginal tinidazole (500 $\mathrm{mg}$ b.i.d) for $14 \mathrm{~d}$ and Lewis et al[61] also report similar success. However, tinidazole is not available for treatment in some countries and is not approved for use in the USA.

In 2000 , the first three cases of metronidazoleresistant $T$. vaginalis from Finland were reported and isolates were also resistant to the 5-nitroimidazole ornidazole[62].

We investigated the activities of 12 new and 1 previously tested nitroimidazole compounds against both metronidazole-susceptible and anaerobically resistant 
T. vaginalis[63]. While 7 out of the 13 drugs were as effective or more effective than metronidazole against susceptible $\mathrm{T}$. vaginalis parasites, anaerobically resistant parasites were cross-resistant to all of the nitroimidazoles and generally displayed the same level of resistance to all drugs.

\section{Alternative chemotherapeutic agents}

There are no recommended alternative treatments for infections with $\mathrm{T}$. vaginalis and the use of alternative antimicrobials has been documented with varied results. Successful treatment with intravaginal paromomycin was described in a 33-year-old female patient suffering recurrent trichomoniasis. However the patient suffered adverse side effects including vulva pain and mucosal ulceration which may facilitate opportunistic infection rendering paromomycin unattractive as a alternative therapeutic[64] (Tab 3). Arsenical and clotrimazole pessaries have also been used in defiant cases with some success[65, 66] and a combination of zinc sulphate douching and moderate doses of metronidazole, thus avoiding the unpleasant side effects of high doses, was successful in four patients suffering from chronic trichomoniasis[67] (Tab 3).

Many compounds have been tested against $\mathrm{T}$. vaginalis in vitro and some are promising. The potent 5-nitrothiazolyl, nitazoxanide, was designed for broadspectrum antiparasitic activity and low toxicity. It is active against a variety of parasites including Cryptosporidium parvum in vivo[68], Entamoeba, Giardia and Blastocystis[69] and appears to be similarly effective against $\mathrm{T}$. vaginalis as metronidazole $[70,71]$. Two series of three trioxanes and 18 disubstituted peroxides were synthesised and evaluated for their trichomonacidal activity with the best compound being about five times more active than metronidazole[72]. Methionine gamma-lyase, the enzyme which catalyzes the single-step conversion of methionine to alpha-ketobutyrate, ammonia, and methanethiol, is highly active in many anaerobic pathogenic microorganisms but has no counterpart in mammals. This pathogen-specific enzyme was exploited as a drug target and the substrate trifluoromethionine was shown to be highly toxic in vitro to $\mathrm{T}$. vaginalis[73].

Because of the wide range of activities of the benzothiazole drugs including neuroprotective, anticonvulsive, antiallergenic, antimicrobial and antitumour, Delmas et al[74] investigated the antitrichomonal activities of a variety of benzothiazoles. Generally they exhibited poor trophozoite toxicity, but two compounds had inhibitory concentrations of 1.6 and $2.9 \mu \mathrm{M}$ in comparison with 3 . $2 \mu \mathrm{M}$ for metronidazole.

Disulfiram is an inhibitor of aldehyde dehydrogenase and is traditionally used in the treatment of alcoholism. The antitrichomonal activity of disulfiram and its metabolite, ditiocarb, were shown to be more effective than metronidazole against both sensitive and resistant trichomonads[75]. Sulphimidazole has two functional groups, one a sulphonamide and the other 5 -nitroimidazole. Since it is active against aerobic and anaerobic bacteria it was tested against 8 strains of metronidazole-sensitive and 4 strains of metronidazole-resistant T. vaginalis[76]. Sulphimidazole exhibited similar activity to metronidazole against sensitive strains and was more effective than metronidazole against the resistant strains (MLCs of $10 \mathrm{mg} / \mathrm{ml}$ and 40- $60 \mathrm{mg} / \mathrm{ml}$, respectively).

\section{CONCLUSIONS}

Although reports of metronidazole-resistant Trichomonas have appeared regularly since the initial case in 1962[77] the incidence of resistance prior to 1996 remained low. However, Sobel et al[78] reported a 17 fold increase in incidence of resistance in 1997-1998 and urge closer surveillance of this resistance. No alternative drugs are approved for treatment of refractory cases which is highly problematic as described in this review with some cases remaining unresolved. Whether continued drug selection has now allowed increased transmission, more resistant organisms, or the emergence of a more serious sexually transmitted disease problem, remains to be monitored. As regards new drugs to treat trichomoniasis, the Trichomonas Genome Project commenced this year will reveal the full range of potential new drug targets.

\section{ACKNOWLEDGMENTS}

Our work in the area of Trichomonas drug susceptibility and resistance has been supported by the National Health and Medical Research Council of Australia and the Australian Centre for Tropical and International Health and Nutrition. 


\section{REFERENCES}

1. Peters W. Recent advances in antimalarial chemotherapy and drug resistance. Adv Parasitol 1974; 12:69-114.

2. Robinson SC. Trichomonal vaginitis resistant to metronidazole. Med Assoc J 1962; 86:665.

3. WHO. Global prevalence and incidence of selected curable sexually transmitted infections (informal publication). 1999.

4. Upcroft P, Upcroft JA. Drug targets and mechanisms of resistance in the anaerobic protozoa. Clin Microbiol Rev $2001 ; 14: 150-64$.

5. Sorvillo F, Kerndt P. Trichomonas vaginalis and amplification of HIV-1 transmission. 1998; 351:213-4.

6. Perez S, Fernandez-Verdugo A, Perez F, Vazquez F. Prevalence of 5-nitroimidazole-resistant trichomonas vaginalis in Oviedo, Spain. Sex Transm Dis 2001; 28:115-6.

7. Lo M, Reid M, Brokenshire M. Resistance of Trichomonas vaginalis infections to metronidazole in Aukland sexual health clinics: report of two cases. N Z Med J 2002; 115:

8. Petrin D, Delgaty K, Bhatt R, Garber G. Clinical and microbiological aspects of Trichomonas vaginalis. Clin Microbiol Rev 1998; 11:300-17.

9. Bui ETN, Johnson PJ. Identification and characterization of [Fe]-hydrogenases in the hydrogenosome of Trichomonas vaginalis. Mol Biochem Parasitol 1996; 76:305-10.

10. Voncken F, Boxma B, Tjaden J, Akhmanova A, Huynen M, Verbeek F, Tielens AG, Haferkamp I, Neuhaus HE, Vogels G, Veenhuis M, Hackstein JH. Multiple origins of hydrogenosomes: functional and phylogenetic evidence from the ADP/ATP carrier of the anaerobic chytrid Neocallimastix sp. Mol Microbiol 2002; 44:1441-54.

11. Ribeiro KC, Mariante RM, Coutinho LL, Benchimol M. Nucleus behavior during the closed mitosis of Tritrichomonas foetus. Biol Cell 2002; 94:289-301.

12. Skerk V, Schonwald S, Krhen I, et al. Aetiology of chronic prostatitis. Int J Antimicrob Agents 2002; 19:471-4.

13. Price MA, Zimba D, Hoffman IF, et al. Addition of treatment for trichomoniasis to syndromic management of urethritis in Malawi: a randomized clinical trial. Sex Transm Dis 2003; 30:516-22.

14. Szarka K, Temesvari P, Kerekes A, Tege A, Repkeny A. Neonatal pneumonia caused by Trichomonas vaginalis. Acta Microbiol Immunol Hung 2002; 49:15-9.

15. Temesvari P, Kerekes A, Tege A, Szarka K. Demonstration of Trichomonas vaginalis in tracheal aspirates in infants with early respiratory failure. J Matern Fetal Neonatal Med 2002; 11:347-9.

16. Saurina GR, McCormack WM. Trichomoniasis in pregnancy. Sex Transm Dis 1997; 24:361-2.

17. Cohen MS. Sexually transmitted diseases enhance HIV transmission: no longer a hypothesis. Lancet 1998; 351: S5-7.

18. Cu-Uvin S, Ko H, Jamieson DJ, et al. Prevalence, incidence, and persistance or recurrence of trichomoniasis among human immunodeficiency virus (HIV)-positive women and among HIV-negative women at high risk for HIV infection. Clin Infect Dis 2002; 34:1406-11.

19. Schwebke JR, Aira T, Jordan N, Jolly PE, Vermund SH.
Sexually transmitted diseases in Ulaanbaatar, Mongolia. Int J STD AIDS. 1998; 9:354-8.

20. Bowden FJ, Paterson BA, Mein J, Savage J, Fairley CK, Garland SM, Tabrizi SN. Estimating the prevalence of Trichomonas vaginalis, Chlamydia trachomatis, Neisseria gonorrhoeae, and human papillomavirus infection in indigenous women in northern Australia. Sex Transm Infect 1999; 75:431-4.

21. Passey M, Mgone CS, Lupiwa S, Tiwara S, Lupiwa T, Alpers MP. Screening for sexually transmitted diseases in rural women in Papua New Guinea: are WHO therapeutic algorithms appropriate for case detection? Bull World Health Organ. 1998; 76:401-11.

22. Mgone CS, Lupiwa T, Yeka W. High prevalence of Neisseria gonorrhoeae and multiple sexually transmitted diseases among rural women in the Eastern Highlands Province of Papua New Guinea, detected by polymerase chain reaction. Sex Transm Dis 2002; 29:775-9.

23. Bowden FJ, Garnett GP. Why is Trichomonas vaginalis ignored? Sex Transm Infect. 1999; 75:372-4.

24. Sorvillo F, Smith L, Kerndt P, Ash L. Trichomonas vaginalis, HIV, and African-Americans. Emerg Infect Dis 2001; 7: 927-32.

25. Durel P, Couture J, Bassoullet MT. The rapid detection of metronidazole in urine. Br J Vener Dis 1967; 43:111-3.

26. Spence MR, Harwell TS, Davies MC, Smith JL. The minimum single oral metronidazole dose for treating trichomoniasis: a randomized, blinded study. Obstet Gynecol 1997; 89:699-703.

27. Martinez V, Caumes E. Metronidazole. Ann Dermatol Venereol 2001; 128:903-9.

28. Upcroft JA, Upcroft P. Drug resistance in Giardia. Parasitol Today 1993; 9:187-90.

29. Kulda J. Trichomonads, hydrogenosomes and drug resistance. Int J Parasitol 1999; 29:199-212.

30. Townson SM, Upcroft JA, Upcroft P. Characterisation and purification of pyruvate:ferredoxin oxidoreductase from Giardia duodenalis. Mol Biochem Parasitol 1996; 79:18393.

31. Brown DM, Upcroft JA, Edwards MR, Upcroft P. Anaerobic bacterial metabolism in the ancient eukaryote Giardia duodenalis. Int J Parasitol 1998; 28:149-64.

32. Jenks PJ, Edwards DI. Metronidazole resistance in Helicobacter pylori. Int J Antimicrob Agents 2002; 19:1-7.

33. M默ler M. The Hydrogenosome. J Gen Microbiol 1993; 139: 2879-89.

34. Upcroft JA, Upcroft P. Drug susceptibility testing of anaerobic protozoa. Antimicrob Agents Chemother 2001; 45:18104.

35. Diniz CG, Santos SG, Pestana A, Farias LM, Carvalho MAR. Chromosomal breakage in the B-fragilis group induced by metronidazole treatment. Anaerobe 2000; 6:149-53.

36. Land KM, Clemens DL, Johnson PJ. Loss of multiple hydrogenosomal proteins associated with organelle metabolism and high-level drug resistance in trichomonads. Exp Parasitol 2001; 97:102-10.

37. Tachezy J, Kulda J, Tomkova E. Aerobic Resistance of Trichomonas vaginalis to metronidazole induced in vitro. Parasitology 1993; 106:31-7. 
38. Rasoloson D, Tomkova E, Cammack R, Kulda J, Tachezy J. Metronidazole-resistant strains of Trichomonas vaginalis display increased susceptibility to oxygen. Parasitology 2001; 123:45-56.

39. Tachezy J, Kulda J. Metronidazole resistance test in vitro in strains of Trichomonas vaginalis isolated from clinical material. 1. Test conditions. Cesk Epidemiol Mikrobiol Imunol 1991; 40:89-96.

40. Tachezy J, Kulda J. Metronidazole resistance test in vitro in strains of Trichomonas vaginalis isolated from clinical material. 2. Proposal for a standard tests. Cesk Epidemiol Mikrobiol Imunol 1991; 40:97-104.

41. Voolmann T, Boreham P. Metronidazole resistant Trichomonas vaginalis in Brisbane. Med J Aust 1993; 159:490.

42. Kulda J, Tachezy J, Cerkasovova A. In vitro induced anaerobic resistance to metronidazole in Trichomonas vaginalis $\mathrm{J}$ Eukaryot Microbiol 1993; 40:262-9.

43. Brown DM, Upcroft JA, Dodd HN, Chen N, Upcroft P. Alternative 2-keto acid oxidoreductase activities in Trichomonas vaginalis. Mol Biochem Parasitol 1999; 98:203-14.

44. Upcroft P. Drug resistance in Giardia: clinical versus laboratory isolates. Drug Resis Updates 1998; 1:166-8.

45. Liu SM, Brown DM, O扗onoghue P, Upcroft P, Upcroft JA. Ferredoxin involvement in metronidazole resistance of Giardia duodenalis. Mol Biochem Parasitol 2000; 108:137-40.

46. Quon DVK, Doliveira CE, Johnson PJ. Reduced transcription of the ferredoxin gene in metronidazole- resistant Trichomonas vaginalis. Proc Natl Acad Sci USA 1992; 89: 4402-6.

47. Mai X, Adams MW. Characterization of a fourth type of 2keto acid-oxidizing enzyme from a hyperthermophilic archaeon: 2-ketoglutarate ferredoxin oxidoreductase from Thermococcus litoralis. J Bacteriol 1996; 178:5890-6.

48. Upcroft JA, Upcroft P. Keto-acid oxidoreductases in the anaerobic protozoa. J Eukaryot Microbiol. 1999; 46:447-9.

49. Land KM, Delgadillo MG, Johnson PJ. In vivo expression of ferredoxin in a drug resistant trichomonad increases metronidazole susceptibility. Mol Biochem Parasitol 2002; 121: 153-7.

50. Rasoloson D, Vanacova S, Tomkova E, et al. Mechanisms of in vitro development of resistance to metronidazole in Trichomonas vaginalis. Microbiology 2002; 148:2467-77.

51. Upcroft P. Multiple-drug resistance in the pathogenic protozoa. Acta Tropica 1994; 56:195-212.

52. Descoteaux S, Ayala P, Samuelson J, Orozco E. Increase in mRNA of multiple Eh pgp genes encoding P-glycoprotein homologues in emetine-resistant Entamoeba histolytica parasites. Gene 1995; 164:179-84.

53. L間ar? D, Cayer S, Singh AK, Richard D, Papadopoulou B, Ouellette M. ABC proteins of Leishmania. J Bioenerg Biomembr 2001; 33:469-74.

54. Banuelos C, Orozco E, Gomez C, et al. Cellular location and function of the P-glycoproteins (EhPgps) in Entamoeba histolytica multidrug-resistant trophozoites. Microb Drug Resist 2002; 8:291-300.

55. Orozco E, Lopez C, Gomez C, et al. Multidrug resistance in the protozoan parasite Entamoeba histolytica. Parasitol Int 2002; 51:353-9.
56. Johnson PJ, Schuck BL, Delgadillo MG. Analysis of a singledomain P-glycoprotein- like gene in the early-diverging protist Trichomonas vaginalis. Mol Biochem Parasitol 1994; 66:127-37.

57. Dudeja PK, Anderson KM, Harris JS, Buckingham L, Coon JS. Reversal of multidrug resistance phenotype by surfactants: relationship to membrane lipid fluidity. Arch Biochem Biophys 1995; 319:309-15.

58. Kaur J, Dey CS. Putative P-glycoprotein expression in arsenite-resistant Leishmania donovani down-regulated by verapamil. Biochem Biophys Res Commun. 2000; 271:6159.

59. Crowell AL, Sanders-Lewis KA, Secor WE. In vitro metronidazole and tinidazole activities against metronidazole-resistant strains of Trichomonas vaginalis. Antimicrob Agents Chemother 2003; 47:1407-9.

60. Sobel JD, Brown W. Tinidazole therapy for metronidazoleresistant vaginal trichomoniasis. Clin Infect Dis 2001; 33: 1341-6.

61. Lewis DA, Habgood L, White R, Barker KF, Murphy SM. Managing vaginal trichomoniasis resistant to high-dose metronidazole therapy. Int J STD AIDS 1997; 8:780-4.

62. Meri T, Jokiranta TS, Suhonen L, Meri S. Resistance of Trichomonas vaginalis to metronidazole: Report of the first three cases from Finland and optimization of in vitro susceptibility testing under various oxygen concentrations. J Clin Microbiol 2000; 38:763-7.

63. Upcroft JA, Campbell RW, Benakli K, Upcroft P, Vanelle P. Efficacy of new 5-nitroimidazoles against metronidazolesusceptible and -resistant Giardia, Trichomonas, and Entamoeba spp. Antimicrob Agents Chemother 1999; 43:73-6.

64. Poppe, WAJ. Nitroimidazole-resistant vaginal trichomoniasis treated with paromomycin. Eur J Obstet Gynecol Reprod Biol 2001; 96:119-20.

65. Watson PG, Pattman RS. Arsenical pessaries in the successful elimination of metronidazole-resistant Trichomonas vaginalis. Int J STD AIDS 1996; 7:296-7.

66. Chen MY, Smith NA, Fox EF, Bingham JS, Barlow D. Acetarsol pessaries in the treatment of metronidazole resistant Trichomonas vaginalis. Int J STD AIDS 2001; 10: 277-80.

67. Houang ET, Ahmet Z, Lawrence AG. Successful treatment of four patients with recalcitrant vaginal trichomoniasis with a combination of zinc sulfate douche and metronidazole therapy. Sex Transm Dis 1997; 24:116-9.

68. Gargala G, Delaunay A, Li X, Brasseur P, Favennec L, Ballet JJ. Efficacy of nitazoxanide, tizoxanide and tizoxanide glucuronide against Cryptosporidium parvum development in sporozoite-infected HCT-8 enterocytic cells. J Antimicrob Chemother 2000; 46:57-60.

69. Gilles HM, Hoffman PS. Treatment of intestinal parasitic infections: a review of nitazoxanide. Trends Parasitol 2002; 18:95-7.

70. Adagu IS, Nolder D, Warhurst DC, Rossignol JF. In vitro activity of nitazoxanide and related compounds against isolates of Giardia intestinalis, Entamoeba histolytica and Trichomonas vaginalis. J Antimicrob Chemother 2002; 49: 103-11. 
71. Cedillo-Rivera R, Chavez B, Gonzalez-Robles A, Tapia A, Yepez-Mulia L. In vitro effect of nitazoxanide against Entamoeba histolytica, Giardia intestinalis and Trichomonas vaginalis trophozoites. J Eukaryot Microbiol 2002; 49:2018.

72. Camuzat-Dedenis B, Provot O, Cointeaux L, et al. Synthesis and in vitro Trichomonacidal activities of some new dialkylperoxides and 1, 2, 4-trioxanes. Eur J Med Chem 2001; 36:837-42.

73. Coombs GH, Mottram JC. Trifluoromethionine, a prodrug designed against methionine gamma-lyase-containing pathogens, has efficacy in vitro and in vivo against Trichomonas vaginalis. Antimicrob Agents Chemother 2001; 45: 1743-5.

74. Delmas F, Di Giorgio C, Robin M, et al. In vitro activities of position 2 substitution-bearing 6 -nitro- and 6-aminobenzothiazoles and their corresponding anthranilic acid derivatives against Leishmania infantum and Trichomonas vaginalis. Antimicrob Agents Chemother 2002; 46:258894.

75. Bouma MJ, Snowdon D, Fairlamb AH, Ackers JP. Activity of disulfiram (bis(diethylthiocarbamoyl)disulphide) and ditiocarb (deithyldithiocarbamate) against metronidazolesensitive and -resistant Trichomonas vaginalis and Tritrichomonas foetus. J Antimicrob Chem 1998; 42:817-
20.

76. Malagoni M, Rossi T, Baggio A, et al. In vitro study of chemotherapeutic activity of sulphimidazole on some sensitive and metronidazole-resistant Trichomonas vaginalis strains. Pharmacol Res 2002; 46:469-72.

77. Lossick JG. Treatment of sexually transmitted vaginosis/ vaginitis. Rev Infect Dis 1990; 12:S665-81.

78. Sobel JD, Nagappan V, Nyirjesy P. Metronidazole-resistant vaginal trichomoniasis-an emerging problem. N Engl J Med 1999; 341:292-3.

79. Snipes LJ, Gamard, PM., Narcisi, EM, Beard, CB, Lehmann, $\mathrm{T}$, Secor, WE. Molecular epidemiology of metronidazole resistance in a population of Trichomonas vaginalis clinical isolates. J Clin Microbiol 2000; 38:3004-9.

80. Perez DG, Gomez C, Paz F, Orozco E. The multidrug-resistance phenotype of Entamoeba histolytica- transfected trophozoites with the EhPgp5 gene. Arch Med Res 2000; 31: S277-8.

81. Saurina G, DeMeo L, McCormack WM. Cure of metronidazole- and tinidazole-resistant trichomoniasis with use of high-dose oral and intravaginal tinidazole. Clin Infect Dis 1998; 26:1238-9.

82. Coelho DD. Metronidazole resistant trichomoniasis successfully treated with paromomycin. Genitourin Med 1997; 73: 397-8. 